\title{
Underutilization of HIV Testing Among Men with Incarceration Histories
}

\author{
Claire E. Farel ${ }^{1,5} \cdot$ Carol E. Golin $^{1,2,3,5} \cdot$ Rebecca D. Ochtera $^{3} \cdot$ David L. Rosen $^{1,5} \cdot$ Marjorie Margolis $^{3}$. \\ Wizdom Powell ${ }^{4}$. David A. Wohl ${ }^{1,5}$
}

Published online: 19 January 2019

○) Springer Science+Business Media, LLC, part of Springer Nature 2019

\begin{abstract}
Annual HIV testing is recommended for individuals at high risk of infection, specifically incarcerated populations. Incarcerated men carry a higher lifetime risk of acquiring HIV than the general population, yet little is known about their HIV testing behaviors. We collected Audio Computer Assisted Self Interview data for 819 men entering a state prison in North Carolina. We assessed correlates of previous HIV testing, including stigmatizing attitudes and beliefs, and explored two outcomes: (1) ever HIV tested before current incarceration, and (2) recency of last HIV test. Eighty percent had been HIV tested before; of those, $36 \%$ reported testing within the last year. Being African American, having education beyond high school, prior incarceration, and higher HIV knowledge increased odds of ever having tested. Results of this study highlight the need to expand HIV testing and education specific to incarcerated populations. Additionally, efforts should be made to monitor and encourage repeat screening.
\end{abstract}

Keywords HIV/AIDS · Utilization · Prevention · Incarcerated population $\cdot$ Testing

Abbreviations
$\begin{array}{ll}\text { HIV } & \text { Human Immunodeficiency Virus } \\ \text { CDC } & \text { The Centers for Disease Control and Prevention } \\ \text { NIMH } & \text { The National Institute of Mental Health } \\ \text { NCDPS } & \text { North Carolina Department of Public Safety } \\ \text { PPC } & \text { Prison Processing Centers } \\ \text { ACASI } & \text { Auto Computer Assisted Self Interview } \\ \text { BRFSS } & \text { Behavioral Risk Factor Surveillance System }\end{array}$

Claire E. Farel

cfarel@med.unc.edu

1 Division of Infectious Diseases, Department of Medicine, University of North Carolina at Chapel Hill School of Medicine, 130 Mason Farm Road, CB\# 7030, Chapel Hill, NC 27599, USA

2 Division of General Internal Medicine and Clinical Epidemiology, University of North Carolina at Chapel Hill School of Medicine, Chapel Hill, NC, USA

3 Department of Health Behavior, University of North Carolina at Chapel Hill Gillings School of Global Public Health, Chapel Hill, NC, USA

4 Health Disparities Institute, University of Connecticut, Hartford, CT, USA

5 Center for AIDS Research, University of North Carolina at Chapel Hill School of Medicine, Chapel Hill, NC, USA

\section{Introduction}

The US Centers for Disease Control and Prevention (CDC) estimates that HIV-positive individuals who are unaware of their status are responsible for $49 \%$ of HIV transmission events yearly [1]. To facilitate timely diagnosis and linkage to care, the CDC recommends routine HIV testing for all individuals ages 13-65. The CDC also recommends annual testing for those at higher HIV risk, including people who inject drugs and their sex partners, persons who engage in transactional sex, sex partners of HIV-infected persons, and persons who themselves or whose sex partners have had more than one sex partner since their most recent HIV test [2]. Specifically, opt-out testing, in which patients are notified that they will be tested unless they decline, and testing in clinical and non-clinical settings, including jails and prisons, is recommended as best practice [3]. For these recommendations to have their intended impact, however, at-risk individuals must first be engaged with the healthcare system. The importance of regular HIV testing (and subsequent access to care and treatment) is underscored by numerous recent studies demonstrating the critical role of undetectable serum HIV viral load to prevent transmission and reduce HIV incidence [4-6]. 
HIV infection rates for incarcerated men have been estimated to be about $2.2 \%$, nearly six times that estimated for all US adults [7-10]. This marked disparity has been explored in other publications from our group and reflects the disproportionate burden of both HIV and incarceration among populations of color, the impact of poverty and poor access to health care, and the disruption of relationships by mass incarceration $[11,12]$. As such, there is an opportunity to target incarcerated populations for HIV testing with subsequent engagement in care for those newly diagnosed and preventative counseling for those found to be HIV negative. However, little is known about HIV testing behaviors of men involved with the US criminal justice system [10]. Of the available research, most studies examine testing within the correctional system rather than in community contexts [9, 13-18].

Studies from two nationally representative datasets (the Behavioral Risk Factor Surveillance System (BRFSS) and National Health Interview Survey (NHIS)) have found multiple factors positively associated with HIV testing in the community, including being 25-50 years old, single, of lower socioeconomic status, being African American, and reporting higher HIV risk behaviors [18, 19]. Higher perceived infection risk and more HIV knowledge were associated with having ever been tested for HIV among people who inject drugs and men who have sex with men [20]. In studies of HIV testing among incarcerated populations, being single, reporting risk behavior, closely knowing someone with HIV/AIDS, having high coping self-efficacy, and endorsing mandatory disclosure of HIV status of inmates were positively associated with HIV test acceptance $[13,15$, 17]. Data are insufficient to determine whether other factors, such as education and stigmatizing attitudes, predict HIV testing behaviors, particularly for high-risk populations [13, $18,21,22]$. To address gaps in knowledge of HIV testing in high-risk populations, we sought to identify factors associated with recent or lifetime HIV testing among men entering a state prison system.

\section{Methods}

This was a sub-study of a large National Institute of Mental Health (NIMH) supported cross-sectional study of randomly selected inmates entering prison in the North Carolina Department of Public Safety (NCDPS) between April 2010 and April 2011 [23]. This study examined inmate HIV prevalence, HIV testing rates, and barriers and facilitators to testing within the NCDPS system. Analyses were conducted in 2011 and 2012. Study participants were enrolled from the seven adult (two female and five male) North Carolina Prison Processing Centers (PPC). The required gateways into the prison system provide health services, including
HIV testing, to inmates at entry. Consistent with all prisons in North Carolina (NC), these PPCs offered HIV testing to all inmates upon entry to the prison system through an opt-out procedure during which inmates were read and asked to sign a general consent form agreeing to medical care that included HIV testing. Inmates were offered the opportunity to ask questions to a nurse regarding the consent form. Inmates at two of the five male PPCs were offered additional HIV education classes before or after HIV testing. Additional details regarding HIV testing procedures in the NCDPS facilities have been published elsewhere [24].

\section{Study Sample}

We utilized data from the five male NC PPCs that conducted intake of all adult male inmates in the state. Eligible participants had to be: at least 18 years of age; able to complete study activities in English; finished with prison processing HIV and sexually transmitted infection (STI) screening activities; not currently held for a violent offense (e.g., rape or murder); and held in the general prison entry population at time of approach. Participants who had previously tested HIV-positive prior to entry or who tested HIV-positive during processing were excluded from analysis.

Eligible inmates were randomly selected weekly from the NCDPS Offender Population Unified System database. Enrollment was stratified by PPC based on the proportion of total inmate entries each facility represented for the previous year. A research assistant screened and obtained informed consent from each potentially eligible inmate in a private, central location within the prison. Eligible inmates who were interested in participating were enrolled and completed study activities.

We used Audio Computer Assisted Self Interview (ACASI) with touch screen technology and headphones to collect data. Participation in the study was voluntary and, per prison policy, no incentives were given for study participation. All study procedures were reviewed and approved by the University of North Carolina Internal Review Board and the NCDPS Human Subjects Review Committee.

\section{Measures}

\section{Dependent Variables}

Participants were asked, "Were you ever tested for HIV BEFORE coming to this processing center? (yes/no)" and, for those answering "yes", "Before coming to this processing center, when was your last HIV test? (month/year)". We used this information to develop two measures of HIV testing behaviors: (1) ever tested for HIV, and (2) recency of last HIV test before incarceration. We analyzed "Ever tested" as a dichotomous variable (yes/no) and "Recency" as a nominal 
variable with 3 categories: (1) never tested, (2) non-recently tested [defined as last tested more than 12 months before completing the survey], and (3) recently tested, [defined as having tested within 12 months of completing the survey].

\section{Independent Variables}

Demographic and behavioral factors: We assessed age, race, education level, and marital status using response categories specified in the 2009 BRFSS [25]. We also asked the number of times previously incarcerated and if the participant had an HIV positive family member or friend.

HIV Knowledge We used an 18-item questionnaire, previously validated among low-literacy groups [26], to measure HIV transmission knowledge. Three additional questions assessed current HIV treatment knowledge: (1) "People who test positive for HIV in prison can get treatment for HIV"; (2) "Right now, there is no cure for HIV"; and (3) "There are drugs that can lengthen the lives of people with HIV.” Response options were True/False/I don't know.

High HIV Acquisition Risk Behavior We used one item from the BRFSS for participants which asked whether they had engaged in at least one of four HIV-associated risk behaviors within the past year (yes/no) without identifying specific behavior(s): (1) used intravenous drugs; (2) treated for a sexually transmitted infection; (3) gave or received money or drugs in exchange for sex; and (4) had anal sex without a condom [25].

Stigma We assessed four theoretically derived sub-components of the stigma process: stereotype, label, blame, and cognitive distance using measures previously validated and shown to be reliable within this population [27]. The items for each sub-component scale were measured on a fourpoint Likert scale ranging from strongly agree to strongly disagree (see Table 1).

\section{Additional Descriptive Variables}

Additionally, we asked whether respondents had had sex with women only, men only, or both women and men (see Table 1). We also asked whether respondents had given or received money, drugs, food, shelter, gifts, or other things in exchange for sex; and concurrency, that is both (a) whether they had had sex with someone while also involved in a sexual relationship with someone else; and (b) whether they had had sex with someone who was also having sex with other people (see Table 1).
Site of Last HIV Test For those who reported having had a prior HIV test, we asked whether that test was conducted: at a street or health fair, in a school or workplace, at an STI clinic or health department; in jail or prison; in a doctor's office; during a hospitalization versus in an emergency department (ED); at a voluntary blood/plasma donation site; or in other settings.

\section{Statistical Analysis}

Sampling was stratified; a weight variable based on population size and racial distribution of each PPC was developed to improve the precision of our estimates. We also used multiple imputation for all predictor variables to enhance regression capabilities and ensure accurately nested models for analysis. In all, five imputed datasets were created using PROC MI procedures. All data preparation was completed using SAS 9.2.

We generated descriptive statistics to define the sample population, using PROC Surveylogistic, taking into account stratum and sampling weights. Next, we used multivariate binomial logistic regression with three nested models to determine the combination of predictors with the greatest explanatory power of "ever testing for HIV" before this incarceration. Model 1 compared demographic variables to the null model. Model 2 introduced knowledge and behaviors thought to be associated with HIV testing. For Model 3, we added stigmatizing attitudes and beliefs variables (labeling, stereotyping, blame, and cognitive distancing) to assess their association with HIV testing.

For participants reporting both ever having tested and date of last test, we then tested associations between our individual correlates and three types of comparative HIV testing behaviors: (1) recent to never testing; (2) nonrecent to never testing; and (3) recent to non-recent testing, using a multinomial logistic regression to compare testing correlates between "recent", "non-recent" and "never" testers.

For these regression analyses, we used PROC Surveylogistic to account for stratum and sampling and PROC MIAnalyze to determine results based on multiple imputation data. We used difference in Wald Chi square scores, taking degrees of freedom into account, to determine significant improvement in model fit $(p<.05)$ as nested model analyses progressed. For both outcomes of interest, AIC was used to determine the best overall model fit. Our findings are presented as odds ratios for each parameter of interest. Nested model analyses also reported ranges in AIC, Wald Chi square, and differences in Wald Chi square for the five imputed datasets. The model deemed most predictive is presented in the results and discussed for each outcome of interest. 
Table 1 Characteristics of men entering NC state prisons between April 2011 and April 2012

\begin{tabular}{|c|c|}
\hline$(\mathrm{N}=819)$ & $\begin{array}{l}\text { Percent- } \\
\text { age }(\mathrm{N}) \text { or } \\
\text { median }\end{array}$ \\
\hline Age (median, range) & $34(18-64)$ \\
\hline \multicolumn{2}{|l|}{ Race $(\%)$} \\
\hline African American & $50(414)$ \\
\hline White & $41(339)$ \\
\hline Other & 9 \\
\hline \multicolumn{2}{|l|}{ Education (\%) } \\
\hline$<$ High school & 38 (306) \\
\hline At least high school & $62(513)$ \\
\hline \multicolumn{2}{|l|}{ Marital status (\%) } \\
\hline Single/never married & $58(471)$ \\
\hline Married/divorced/widowed & $42(348)$ \\
\hline Had prior incarceration (\%) & $57(461)$ \\
\hline $\begin{array}{l}\text { Engaged in at least one of four High HIV Risk Behaviors (sex exchange, anal sex, intravenous drug use, concurrent sexual part- } \\
\text { ners) in last year }(\%)\end{array}$ & $26(211)$ \\
\hline Know someone living with HIV (\%) & $39(317)$ \\
\hline \multicolumn{2}{|l|}{ Did the HIV test you had while at this processing center show that you have HIV? ${ }^{\mathrm{a}}$} \\
\hline No & $75(531 / 705)$ \\
\hline Don’t know & $25(174 / 705)$ \\
\hline Attended the HIV class during this incarceration ${ }^{\mathrm{b}}$ & $73(617 / 844)$ \\
\hline \multicolumn{2}{|l|}{ During the 3 months before this incarceration, had sex with ${ }^{c}$} \\
\hline Women only & $97(744 / 766)$ \\
\hline Men only & $1(8 / 766)$ \\
\hline Both women and men & $<1(5 / 766)$ \\
\hline Gave money, drugs, food, shelter, gifts, or other things in exchange for $\mathrm{sex}^{\mathrm{c}}$ & $10(76 / 766)$ \\
\hline Received money, drugs, food, shelter, gifts, or other things needed, in exchange for $\operatorname{sex}^{c}$ & $6(46 / 766)$ \\
\hline Had sex with someone while also involved in a sexual relationship with someone else ${ }^{\mathrm{d}}$ & $74(299 / 402)$ \\
\hline Had sex with someone who was also having sex with other people ${ }^{c}$ & $40(306 / 766)$ \\
\hline
\end{tabular}

\begin{tabular}{|c|c|c|c|}
\hline \multicolumn{4}{|c|}{ Factor 1: Label $(n=980)$} \\
\hline \multicolumn{4}{|c|}{ On a scale of __ to __, people with HIV (are)... } \\
\hline L1 & Careful/careless & 3.48 & .047 \\
\hline L2 & Heterosexual/homosexual & 3.53 & .040 \\
\hline L3 & Doesn't put others at risk/puts others at risk & 3.53 & .040 \\
\hline L4 & Not drug users/drug users & 3.60 & .047 \\
\hline L5 & No sex partners/lots of sex partners & 3.71 & .050 \\
\hline \multicolumn{4}{|c|}{ Factor 2: Stereotype-negative attributes $(n=980)$} \\
\hline \multicolumn{4}{|c|}{ On a scale of __ to __, people with HIV (are)... } \\
\hline S1 & Caring/uncaring & 2.65 & .025 \\
\hline S2 & Good people/bad people & 2.70 & .037 \\
\hline S3 & Friendly/unfriendly & 2.58 & .043 \\
\hline S4 & Reliable/unreliable & 2.89 & .034 \\
\hline S5 & Nice/not nice & 2.34 & .042 \\
\hline
\end{tabular}


Table 1 (continued)

\begin{tabular}{|c|c|c|c|c|c|c|c|}
\hline \multicolumn{8}{|c|}{ Expressed stigma variables } \\
\hline & & \multicolumn{2}{|c|}{ Disagree a lot } & \multicolumn{2}{|c|}{$\begin{array}{l}\text { Disagree a } \\
\text { little }\end{array}$} & Agree a little & Agree a lot \\
\hline \multicolumn{8}{|c|}{ Factor 3: blame $(n=960)$} \\
\hline B1 & People who have HIV have caused their own misery & \multicolumn{2}{|l|}{.38} & \multicolumn{2}{|c|}{.29} & .23 & .11 \\
\hline B2 & People with HIV must have done something wrong to get it & \multicolumn{2}{|l|}{.34} & \multicolumn{2}{|c|}{.22} & .20 & .25 \\
\hline B3 & $\begin{array}{l}\text { Getting HIV is the price people pay for choosing to do the } \\
\text { wrong things }\end{array}$ & \multicolumn{2}{|l|}{.41} & \multicolumn{2}{|c|}{.21} & .26 & .12 \\
\hline B4 & People who have HIV deserve what happens to them & \multicolumn{2}{|l|}{67} & \multicolumn{2}{|c|}{.25} & .07 & .03 \\
\hline B5 & Getting HIV is punishment for being a sinner & \multicolumn{2}{|l|}{.71} & \multicolumn{2}{|c|}{.17} & .07 & .05 \\
\hline \multicolumn{8}{|c|}{ Factor 4: Cognitive Distance $(n=970)$} \\
\hline $\mathrm{C} 1$ & I'm perfectly safe from getting HIV & \multicolumn{2}{|l|}{.36} & \multicolumn{2}{|c|}{.24} & .21 & .19 \\
\hline $\mathrm{C} 2$ & Getting HIV is not something I really need to worry about & \multicolumn{2}{|l|}{.49} & \multicolumn{2}{|c|}{.21} & .15 & .15 \\
\hline $\mathrm{C} 3$ & HIV is not my problem & \multicolumn{2}{|l|}{.48} & \multicolumn{2}{|c|}{.22} & .13 & .18 \\
\hline $\mathrm{C} 4$ & I'm not the kind of person that gets HIV & \multicolumn{2}{|l|}{.29} & \multicolumn{2}{|c|}{.24} & .20 & .27 \\
\hline Intenc & discrimination variables & & & & & & \\
\hline Socia & istance $(n=957)$ & & Disagre & & $\begin{array}{l}\text { Disagree a } \\
\text { little }\end{array}$ & a Agree a little & Agree a lot \\
\hline I wou & not want... & & & & & & \\
\hline D1 & To hang out with a person who has HIV & & .43 & & .31 & .13 & .13 \\
\hline D2 & To use the same shower than a person with HIV used & & .36 & & .29 & .18 & .17 \\
\hline D3 & I feel uncomfortable around persons with HIV ${ }^{1}$ & & .36 & & .27 & .22 & .16 \\
\hline D4 & To be friends with a person who has HIV & & .49 & & .34 & .11 & .07 \\
\hline D5 & Work with a person who has HIV & & .35 & & .34 & .19 & .12 \\
\hline D6 & To drink from a water fountain if a person with HIV had used it & & .37 & & .30 & .16 & .18 \\
\hline D7 & A person with HIV to be in a cell with me & & .21 & & .21 & .26 & .32 \\
\hline D8 & To play sports, like basketball or volleyball, with a person who ha & HIV & .34 & & .27 & .19 & .21 \\
\hline D9 & A person with HIV working in the prison kitchen & & .16 & & .14 & .20 & .51 \\
\hline
\end{tabular}

Intended discrimination variables

\begin{tabular}{|c|c|c|c|c|c|}
\hline \multicolumn{2}{|c|}{ Support for mandatory disclosure policy $(n=951)$} & \multirow{2}{*}{$\begin{array}{l}\begin{array}{l}\text { Strongly } \\
\text { disagree }\end{array} \\
.15\end{array}$} & \multirow{2}{*}{$\begin{array}{l}\text { Disagree } \\
.25\end{array}$} & \multirow{2}{*}{$\begin{array}{l}\text { Agree } \\
.22\end{array}$} & \multirow{2}{*}{$\begin{array}{l}\text { Strongly agree } \\
.39\end{array}$} \\
\hline P1 & Outside of prison, people should be able to find out who in the community has HIV & & & & \\
\hline $\mathrm{P} 2$ & In prison, correctional officers should be able to find out which inmates have HIV & .16 & .16 & .21 & .48 \\
\hline P3 & In prison, inmates should be able to find out which other inmates have HIV & .20 & .24 & .16 & .40 \\
\hline
\end{tabular}

a 705 participants who indicated they knew they were offered HIV test

b844 participants asked about whether they were offered HIV education class

${ }^{\mathrm{c}} 766$ participants who were asked about these risk behaviors

${ }^{\mathrm{d}} 402$ participants asked about this risk behavior

\section{Results}

Of the 856 incarcerated men interviewed, 819 reported information regarding their prior HIV testing behavior and, thus comprised the final sample. Of the 819,777 also reported the date of their most recent test (including if they had never had a previous test) and created the subsample for assessing correlates of test recency. Sample characteristics are reported in Table 1, including descriptive statistics of the stigma scale items.

Eighty percent $(n=652)$ of participants reported "ever testing" for HIV before their current incarceration. Of the 610 who also reported the date of their last HIV test, $36 \%$ $(n=222)$ reported testing for HIV within the last year. Of the 624 who had ever tested and who reported information about where they had the their last test, $11 \%(n=71)$ reported testing at an STI clinic/county health department; $10 \%(n=65)$ 
in prison; $9 \%(n=54)$ in jail; 6\% $(n=38)$ in voluntary blood/ plasma donation sites: $5 \%(n=34)$ in doctor's offices; $4 \%$ $(n=24)$ in hospitals (not in the ED); $3 \%(n=18)$ at street/ health fairs; $2 \%(n=16)$ in emergency rooms; $1 \%(n=6)$ at school/work; and 2\% $(n=14)$ reported other as the site of their last test.

For "ever" testing analyses, Model 1 demonstrated improved fit over the null model, and Model 2 demonstrated statistically significant improvement in fit compared to Model $1(p=.03)$. Model 3 did not show statistically significant improvement in fit over Model $2(p=.32-.61)$; however, it was determined to have the best overall fit based on AIC. This final model showed being African American, having greater than a high school education, serving a previous prison sentence, and having greater HIV knowledge were each independently associated with a higher odds of having ever tested for HIV. Self-reported risk behavior was not associated with ever testing for HIV (Table 2). For test recency analyses, Model 1 improved model fit over the null based on AIC. Models 2 and 3 did not improve model fit $(p=.98-.99)$. However, Model 3 offered the best fit to the data based on AIC scores (Table 3).

When comparing "recent testing" to "never testing" for HIV, African Americans and those reporting younger age had significantly greater odds of having had an HIV test within the 12 months prior to incarceration in the final model (Table 3). African American race, having greater than a high school education, and greater HIV knowledge were significantly related to "non-recent testing" when compared to "never testing" for HIV. When comparing "recent" to "non-recent" HIV testing, respondents reporting African American race and those reporting being single/never married were more likely to be "recent testers. "Self-reported risk was not associated with temporal pattern of HIV testing.

\section{Discussion}

This study demonstrated that a relatively high percentage of NC state prison inmates (80\%) have previously received an HIV test. Previous studies estimated that $45 \%$ of US adults [28] and 63\% of prison inmates have previously received an HIV test [29]. While our sample exhibited slightly higher rates of HIV testing than prior samples of inmates, only $27 \%$ of our sample (36\% of men who reported having an HIV test) had been tested within the last year, despite CDC recommendations for annual testing for persons at higher risk of infection.

Previous research has shown incarcerated populations are at greater risk of HIV aquisition than the general population $[9,10]$; over one-fourth $(26 \%)$ of our sample reported at least one of four high risk behaviors (sex exchange, anal sex, intravenous drug use, or concurrent sexual partners) in
Table 2 Results of final nested multivariate models of correlates of ever HIV testing within the population

\begin{tabular}{|c|c|c|}
\hline \multirow[t]{2}{*}{ Parameter $(\mathrm{N}=819)$} & \multicolumn{2}{|l|}{ Final model } \\
\hline & OR & CI \\
\hline Intercept & 1.21 & $(.31,4.89)$ \\
\hline Age & .98 & $(.96,1.01)$ \\
\hline \multicolumn{3}{|l|}{ Race $^{\mathrm{a}}$} \\
\hline White & $.40 * *$ & $(.27, .61)$ \\
\hline Other & .94 & $(.44,1.98)$ \\
\hline \multicolumn{3}{|l|}{ Education $^{\mathrm{b}}$} \\
\hline High school & 1.25 & $(.83,1.87)$ \\
\hline Beyond high school & $1.98 *$ & $(1.15,3.41)$ \\
\hline \multicolumn{3}{|l|}{ Marital status ${ }^{c}$} \\
\hline Married & 1.23 & $(.71,2.14)$ \\
\hline Other & 1.19 & $(.71,2.00)$ \\
\hline Prison recidivism & $1.15 *$ & $(1.00,1.32)$ \\
\hline Risk behavior & .99 & $(.65,1.51)$ \\
\hline Know HIV + other & 1.25 & $(.83,1.87)$ \\
\hline HIV knowledge & $1.07 * *$ & $(1.02,1.12)$ \\
\hline \multicolumn{3}{|l|}{ Stigma } \\
\hline Label & 1.03 & $(.99,1.08)$ \\
\hline Stereotype & 1.01 & $(.96,1.04)$ \\
\hline Blame & 1.00 & $(.95,1.06)$ \\
\hline Cognitive distance & .96 & $(.91,1.02)$ \\
\hline AIC range & $(21113.32,21161.33)$ & \\
\hline Wald $x^{2}$ range & $(47.49,50.14)$ & \\
\hline Wald diff & $(2.72,4.81)$ & \\
\hline$p$ value & $(.32, .61)$ & \\
\hline
\end{tabular}

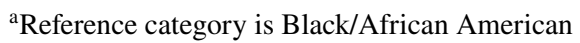

${ }^{\mathrm{b}}$ Reference category is no high school degree or equivalent

${ }^{\mathrm{c}}$ Reference category is single, never married; Null AIC $=22729.197$; Boldface indicates statistical significance $\left({ }^{*} p<0.05\right.$, $\left.* * p<0.01\right)$

the year prior to incarceration. HIV risk behaviors have been associated with ever testing and with recent testing for highrisk and prison-specific groups [15, 17, 19, 20]. However, we found no association between these high-risk behaviors and ever or recent HIV testing.

This result may be due to the dichotomous measure, which was designed to identify individuals at the highest risk. Moreover, while 26\% $(n=211)$ of the cohort reported such high risk, the vast majority $(86.9 \%)$ of male inmates in this study reported at least one HIV risk factor [30]. Overall, these findings suggest the need for more active assessment of risk behaviors and reinforcement of follow-up HIV testing among those who report risk behaviors. Efforts to sustain HIV testing may be markedly different from those designed to elicit initial testing.

Achieving a level of education beyond high school had the greatest relationship with testing. This consistently results in twice the odds of ever and non-recent testing 
Table 3 Results of final nested multivariate model analyses exploring correlates of recency of HIV testing

\begin{tabular}{|c|c|c|c|c|c|c|}
\hline \multirow[t]{3}{*}{ Parameter $(\mathrm{N}=777)$} & \multicolumn{6}{|c|}{ Final model } \\
\hline & \multicolumn{2}{|c|}{$\begin{array}{l}\text { Recent compared to never } \\
\text { test }\end{array}$} & \multicolumn{2}{|c|}{$\begin{array}{l}\text { Non-recent compared to } \\
\text { never test }\end{array}$} & \multicolumn{2}{|c|}{$\begin{array}{l}\text { Recent compared to } \\
\text { non-recent test }\end{array}$} \\
\hline & OR & $\mathrm{CI}$ & OR & CI & OR & CI \\
\hline Intercept & .48 & $(.10,2.41)$ & .55 & $(.11,2.40)$ & .92 & $(.25,3.43)$ \\
\hline Age & $.97 *$ & $(.94, .99)$ & .99 & $(.97,101)$ & .98 & $(.96,1.00)$ \\
\hline \multicolumn{7}{|l|}{ Race $^{\mathrm{a}}$} \\
\hline White & $.25 * *$ & $(.15, .40)$ & $.55 * *$ & $(.36, .85)$ & $.44 * *$ & $(.29, .67)$ \\
\hline Other & .62 & $(.26,1.51)$ & 1.27 & $(.58,2.78)$ & $.49 *$ & $(.26, .94)$ \\
\hline \multicolumn{7}{|l|}{ Education $^{\mathrm{b}}$} \\
\hline High school & 1.28 & $(.78,2.10)$ & 1.33 & $(.86,2.08)$ & .96 & $(.63,1.45)$ \\
\hline Beyond high school & 2.01 & $(1.06,3.84)$ & $2.15 * *$ & $(1.21,3.81)$ & .94 & $(.57,1.53)$ \\
\hline \multicolumn{7}{|l|}{ Marital status ${ }^{\mathrm{c}}$} \\
\hline Married & .86 & $(.43,1.70)$ & 1.52 & $(.85,2.72)$ & $.57 *$ & $(.33, .97)$ \\
\hline Other & 1.15 & $(.62,2.11)$ & 1.20 & $(.69,1.08)$ & .96 & $(.59,1.56)$ \\
\hline Prison recidivism & 1.16 & $(1.00,1.34)$ & 1.13 & $(.98,1.30)$ & 1.02 & $(.94,1.11)$ \\
\hline Risk Behavior & 1.08 & $(.65,1.81)$ & .95 & $(.60,1.50)$ & 1.53 & $(.75,1.71)$ \\
\hline Know HIV + other & 1.29 & $(.79,2.09)$ & 1.17 & $(.76,1.80)$ & 1.10 & $(.75,1.61)$ \\
\hline HIV knowledge & 1.07 & $(1.01,1.13)$ & $1.08 * *$ & $(1.03,1.14)$ & .99 & $(.94,1.04)$ \\
\hline \multicolumn{7}{|l|}{ Stigma } \\
\hline Label & 1.05 & $(1.00,1.11)$ & 1.03 & $(.98,1.07)$ & 1.03 & $(.98,107)$ \\
\hline Stereotype & 1.01 & $(.96,1.06)$ & 1.00 & $(.96,1.05)$ & 1.01 & $(.97,1.04)$ \\
\hline Blame & .99 & $(.92,1.07)$ & 1.01 & $(.94,1.07)$ & .99 & $(.93,1.05)$ \\
\hline Cognitive distance & .98 & $(.92,1.05)$ & .95 & $(.89,1.02)$ & 1.03 & $(.99,1.09)$ \\
\hline AIC & \multicolumn{6}{|c|}{$(41794.30,41832.31)$} \\
\hline Wald $x^{2}$ & \multicolumn{6}{|c|}{$(87.27,87.69)$} \\
\hline Wald diff & \multicolumn{6}{|c|}{$(7.82,8.84)$} \\
\hline $\mathrm{p}$ value & \multicolumn{6}{|c|}{$(.99, .99)$} \\
\hline
\end{tabular}

${ }^{\text {a }}$ Reference category is African American race

${ }^{b}$ Reference category is no high school degree or equivalent

${ }^{\mathrm{c}}$ Reference category is single, never married; Null Model AIC $=44518.257$; Boldface indicates statistical significance $(* \mathrm{p}<0.05, * * \mathrm{p}<0.01)$ compared to those with less than a high school education. Similarly, independent of education level, greater knowledge of HIV showed statistically significant associations with testing behaviors. In a separate analysis from our group, low knowledge of HIV was associated with higher expression of HIV stigma and reluctance to undergo testing [31]. These findings highlight benefits of greater HIV knowledge and affirm that prisons are relevant venues for HIV education and routinization of HIV testing through opt-out programs.

Our finding of a positive association between previous incarceration and ever testing for HIV also highlights the essential role prison systems play in providing HIV education and testing. The nearly one-fifth $(19 \% ; n=119)$ of those with a previous test conducted in jail or prison, provide support for these findings. However, nearly half the members of our sample were not recidivists. Community providers should inquire about HIV and incarceration risk behaviors, as well as last testing date among patients with a history of incarceration or risky behaviors. In cases of uncertain last test dates or results, providers should err on the side of repeat screening. Moreover, policies, such as Medicaid expansion to those involved in the criminal justice system, including released prisoners, may encourage engagement in medical care and bridge post-incarceration testing gaps.

The paucity of factors associated with test recency suggests that demographic and behavioral factors beyond race, education, and knowledge may be salient to test recency. Environmental indicators, such as access and availability of testing, which may be more closely associated with test recency, were not accounted for in this study [16, 22]. More research is needed to better understand these results and the effect of access to care and testing availability on testing frequency. A longitudinal cohort study of prisoners that follows men in and out of prison would be ideal.

Additionally, for every year increase in age, men had a 3\% lower odds of having recently tested than they had of never 
testing. This finding may represent greater acceptance of routine HIV testing among younger men, or possibly reflect HIV testing in community settings targeting younger men. As HIV diagnosed among those aged 50 and greater is more likely to be late stage [32], there needs to be continued attention to HIV screening in older incarcerated and formerly incarcerated men.

HIV stigmatizing attitudes were not associated with testing behaviors. An inmate study assessing the association between HIV stigma and HIV testing behaviors found inmates with higher HIV testing-specific stigma tested less during incarceration [13]. Our findings point to potentially similar associations for testing. One potential explanation could be that inmates received opt-out testing in a prison or healthcare setting. Opt-out HIV testing, in which an organization (e.g., prison, healthcare center) routinely tests all individuals [33], may reduce the influence of stigma on HIV testing by making testing normative. Opt-out testing has been shown to increase the number of inmates who receive HIV testing in prisons compared to risk-based testing [34]. We have not identified prior studies that assessed the association between stigmatizing attitudes and pre-incarceration HIV testing. Additional studies to determine the relationship between testing-specific stigma and HIV testing outside of the prison system would be an important next step in understanding testing behaviors among this population.

\section{Limitations}

This cross-sectional study precludes the assessment of temporal relationships. The self-reported nature of our outcome variable could also have introduced recall and social desirability biases into our study. While we had information about the setting of the most recent HIV test prior to this incarceration among those who had a previous test, we did not have information about the settings of all their previous tests. Of particular interest is how many, if any, were tested in jail beforetheir prison incarceration. While we did not collect information specific to prior jail testing for this study (beyond what was reported by participants related to their most recent test), few jails in NC routinely conducted HIV testing at the time of this assessment [17].

Because variables used in this study focused specifically on personal attributes, attitudes, and behaviors, we could not assess structural and environmental influences on participants' decisions to be tested for HIV. As in other studies [16, 19, 20, 22], availability, accessibility, and peer norms may play a significant role in testing decisions. Further research incorporating these variables is warranted. Lastly, as this work focused on men; studies of community HIV testing of women are warranted.
Despite limitations, our findings suggest that white men with less education and less HIV knowledge are missing from existing HIV testing programs. The use of random selection for enrollment and stratification by prison facility suggest these data can be considered representative of the male NC prison population. Data collection via ACASI helped to ensure accurate data collection and increased our capacity to enroll persons with lower literacy levels. Combined, these strengths enhance our ability to generalize results, which have important implications for intervention recommendations. Moreover, this study adds novel and important information to the HIV testing literature for a population at risk of HIV.

\section{Conclusions}

Those with a history of incarceration are at higher HIV risk than the general population. Our data suggest that HIV screening of men at risk for incarceration and those who are released from prison is suboptimal. While most newly incarcerated individuals in this study had previously been tested for HIV, few had been tested recently_-despite a relatively high prevalence of self-reported HIV risk behaviors.

We identified several factors-education level, HIV knowledge, race, and age-associated with testing and recent testing that point to gaps in current HIV screening strategies. Disclosure of sensitive social history, including sexual practices, substance abuse, and criminal justice involvement, may be limited by stigma and, often, reluctance among providers to explore such topics [35-37]. However, they are an important component of a comprehensive medical history and training to enhance communication between patient and provider could help reduce HIV testing barriers and improve patient care [38, 39]. Contact with the health care system, now expanded by the Affordable Care Act and Medicaid expansion with financial incentives for preventative testing (in some states) [40], in addition to initiatives such as nurse-initiated testing and electronic medical record prompts [41-44], will likely provide enhanced opportunities for provider-patient conversation related to routine HIV screening and other recommended testing among incarcerated populations [45].

We hope that insights from this study can support accessible and effective interventions to facilitate detection of HIV among at-risk populations. Importantly, pairing testing efforts with prompt initiation of antiretroviral therapy and durable linkage to HIV care can ensure healthier lives for incarcerated and previously incarcerated individuals and their communities.

Acknowledgements This research was funded by the National Institute on Mental Health (R01 MH079720), National Institute on Drug Abuse 
(K24DA037101), and Eunice Kennedy Shriver National Institute of Childhood and Human Development, National Institute of Allergy and Infectious Diseases (K24HD06920); University of North Carolina Center for AIDS Research (AI050410). Drs. Ochtera, Golin, Powell, Rosen and Wohl participated in the research design and execution. Dr. Ochtera performed data analyses with Dr. Golin. Drs. Ochtera, Golin, Farel and Ms. Margolis wrote this article with input from Drs. Wohl, Rosen and Powell and with editorial assistance from Caitlin Biddell, Allison Pack, and Breana Castonguay. Brian Barkley and Dr. David Rosen assisted with final data analyses and preparation. None of the authors of this paper have reported conflicts of interest or financial disclosures. The authors thank the study participants, the North Carolina Department of Public Safety, and the wardens and staff of the participating facilities for their support of this project. This research would not have been possible without the assistance of the University of North Carolina at Chapel Hill Center for AIDS Research Criminal Justice Working Group.

\section{Compliance with Ethical Standards}

Conflict of interest No conflicts of interest were reported by the authors of this paper. The authors certify that they have no affiliations with or involvement in any organization or entity with any financial or non-financial interest in the subject matter or materials discussed in this manuscript.

Ethical Approval All procedures performed in studies involving human participants were in accordance with the ethical standards of the institutional and/or national research committee and with the 1964 Helsinki declaration and its later amendments or comparable ethical standards. Informed consent was received from all participants.

\section{References}

1. Hall HI, Holtgrave DR, Maulsby C. HIV transmission rates from persons living with HIV who are aware and unaware of their infection. AIDS. 2012;26(7):893-6.

2. Branson BM, Handsfield HH, Lampe MA, Janssen RS, Taylor AW, Lyss SB, et al. Revised recommendations for HIV testing of adults, adolescents, and pregnant women in health-care settings. MMWR Recomm Rep. 2006;55(RR-14):1-17.

3. Anderson TJ, Atkins D, Baker-Cirac C, Bayer R, de Palomo FKB, Bolan GA, et al. Revised guidelines for HIV counseling, testing, and referral and revised recommendations for HIV screening of pregnant women. MMWR Reccom Rep. 2001;50(19):63-85.

4. Bavinton BR, Pinto AN, Phanuphak N, Grinsztejn B, Prestage GP, Zablotska-Manos IB, et al. Viral suppression and HIV transmission in serodiscordant male couples: an international, prospective, observational, cohort study. Lancet HIV. 2018;5(8):e438-47.

5. Cohen MS, Chen YQ, McCauley M, Gamble T, Hosseinipour MC, Kumarasamy N, et al. Prevention of HIV-1 infection with early antiretroviral therapy. N Engl J Med. 2011;365(6):493-505.

6. Rodger AJ, Cambiano V, Bruun T, Vernazza P, Collins S, Van Lunzen J, et al. Sexual activity without condoms and risk of HIV transmission in serodifferent couples when the HIV-positive partner is using suppressive antiretroviral therapy. JAMA. 2016;316(2):171-81.

7. Gaiter J, Doll S. Improving HIV/AIDS prevention in prisons is good public health policy. Am J Public Health. 1996;86(9):1201-3.
8. McQuillan GM, Kruszon-Moran D. HIV infection in the United States household population aged 18-49 years: results from 1999-2006. 2008. Report No.: 4.

9. Spaulding A, Stephenson B, Macalino G, Ruby W, Clarke JG, Flanigan TP. Human immunodeficiency virus in correctional facilities: a review. Clin Infect Dis. 2002;35(3):305-12.

10. Spaulding AC, Seals RM, Page MJ, Brzozowski AK, Rhodes W, Hammett TM. HIV/AIDS among inmates of and releasees from US correctional facilities, 2006: declining share of epidemic but persistent public health opportunity. PLoS ONE. 2009;4(11):e7558.

11. Rich JD, DiClemente R, Levy J, Lyda K, Ruiz M, Rosen DL, et al. Correctional facilities as partners in reducing HIV disparities. J Acquir Immune Defic Syndr. 2013;63(01):49.

12. Rosen DL, Schoenbach VJ, Wohl DA, White BL, Stewart PW, Golin CE. Characteristics and behaviors associated with HIV infection among inmates in the North Carolina prison system. Am J Public Health. 2009;99(6):1123-30.

13. Andrinopoulos K, Kerrigan D, Figueroa JP, Reese R, Ellen JM. HIV coping self-efficacy: a key to understanding stigma and HIV test acceptance among incarcerated men in Jamaica. AIDS Care. 2010;22(3):339-47.

14. Behrendt C, Kendig N, Dambita C, Horman J, Lawlor J, Vlahov D. Voluntary testing for human immunodeficiency virus (HIV) in a prison population with a high prevalence of HIV. Am J Epidemiol. 1994;139(9):918-26.

15. Burchell AN, Calzavara LM, Myers T, Schlossberg J, Millson M, Escobar M, et al. Voluntary HIV testing among inmates: sociodemographic, behavioral risk, and attitudinal correlates. J Acquir Immune Defic Syndr. 2003;32(5):534-41.

16. Kacanek D, Eldridge GD, Nealey-Moore J, MacGowan RJ, Binson D, Flanigan TP, et al. Young incarcerated men's perceptions of and experiences with HIV testing. Am J Public Health. 2007;97(7):1209-15.

17. Rosen DL, Schoenbach VJ, Wohl DA, White BL, Stewart PW, Golin CE. An evaluation of HIV testing among inmates in the North Carolina prison system. Am J Public Health. 2009;99(Suppl 2):S452-9.

18. Rountree MA, Chen L, Brown A, Pomeroy EC. HIV testing rates and testing locations, by race and ethnicity. Health Soc Work. 2009;34(4):247-55.

19. Ostermann J, Kumar V, Pence BW, Whetten K. Trends in HIV testing and differences between planned and actual testing in the United States, 2000-2005. Arch Intern Med. 2007;167(19):2128-35.

20. Kellerman SE, Lehman JS, Lansky A, Stevens MR, Hecht FM, Bindman $\mathrm{AB}$, et al. HIV testing within at-risk populations in the United States and the reasons for seeking or avoiding HIV testing. J Acquir Immune Defic Syndr. 2002;31(2):202-10.

21. Kalichman SC, Simbayi LC. HIV testing attitudes, AIDS stigma, and voluntary HIV counselling and testing in a black township in Cape Town. South Africa. Sex Transm Infect. 2003;79(6):442-7.

22. Obermeyer CM, Osborn M. The utilization of testing and counseling for HIV: a review of the social and behavioral evidence. Am J Public Health. 2007;97(10):1762-74.

23. Wohl DA, Golin C, Rosen DL, May JM, White BL. Detection of undiagnosed HIV among state prison entrants. JAMA. 2013;310(20):2198-9.

24. Rosen DL, Golin CE, Grodensky CA, May J, Bowling JM, DeVellis RF, et al. Opt-out HIV testing in prison: informed and voluntary? AIDS Care. 2015;27(5):545-54.

25. Centers for Disease Control and Prevention. Behavioral risk factor surveillance system survey data. Atlanta, GA: U.S. Department of Health and Human Services; 2009. 
26. Carey MP, Schroder KE. Development and psychometric evaluation of the brief HIV knowledge questionnaire. AIDS Educ Prev. 2002;14(2):172-82.

27. Ochtera R, Golin C, DeVellis RF, Zimmer C, Nyblade L, Wohl DA. New insights into defining and measuring HIV-associated stigma: an empirical test of a theoretically based conceptual model. Under Review.

28. Centers for Disease Control and Prevention. HIV testing trends in the United States, 2000-2011. Atlanta, GA: U.S. Department of Health and Human Services, Centers for Disease Control and Prevention; 2013.

29. Maruschak L. HIV in prisons and jails, 2002. U.S. Department of Justice, Bureau of Justice Statistics Bulletin; 2004.

30. Golin C, Biddell C, Barkley B. Discrepancy between perceptions of and actual HIV risk among inmates in a state prison system. In preparation.

31. Muessig KE, Rosen DL, Farel CE, White BL, Filene EJ, Wohl DA. "Inside these fences is our own little world": prison-based HIV testing and HIV-related stigma among incarcerated men and women. AIDS Educ Prev. 2016;28(2):103-16.

32. Centers for Disease Control and Prevention. HIV among people aged 50 and older. Atlanta, GA: Division of HIV/AIDS Prevention, National Center for HIV/AIDS, Viral Hepatitis, STD, and TB Prevention, Centers for Disease Control and Prevention; 2018. https://www.cdc.gov/hiv/group/age/olderamericans/index.html.

33. Galletly CL, Pinkerton SD, Petroll AE. CDC recommendations for opt-out testing and reactions to unanticipated HIV diagnoses. AIDS Patient Care STDs. 2008;22(3):189-93.

34. Westergaard RP, Spaulding AC, Flanigan TP. HIV among persons incarcerated in the USA: a review of evolving concepts in testing, treatment, and linkage to community care. Curr Opin Infect Dis. 2013;26(1):10-6.

35. Burke RC, Sepkowitz KA, Bernstein KT, Karpati AM, Myers JE, Tsoi BW, et al. Why don't physicians test for HIV? A review of the US literature. AIDS. 2007;21(12):1617-24.

36. Hudson AL, Heilemann MV, Rodriguez M. Missed opportunities for universal HIV screening in primary care clinics. J Clin Med Res. 2012;4(4):242-50.

37. Zheng MY, Suneja A, Chou AL, Arya M. Physician barriers to successful implementation of US Preventive Services Task Force routine HIV testing recommendations. J Int Assoc Provid AIDS Care. 2014;13(3):200-5.

38. Stewart MA. Effective physician-patient communication and health outcomes: a review. CMAJ. 1995;152(9):1423-33.

39. Wilcox L, Patel R, Back A, Czerwinski M, Gorman P, Horvitz E, et al. Patient-clinician communication: the roadmap for HCI. In: Ext Abstr Hum Factors Computing Syst. 2013. p. 3291-4.

40. United States Department of Health and Human Services. Key features of the affordable care act by year. In: Institute of Medicine (ed.) The impacts of the affordable care act on preparedness resources and programs: workshop summary. Washington, DC: National Academies Press; 2014.

41. Anaya HD, Hoang T, Golden JF, Goetz MB, Gifford A, Bowman $\mathrm{C}$, et al. Improving HIV screening and receipt of results by nurseinitiated streamlined counseling and rapid testing. J Gen Intern Med. 2008;23(6):800-7.

42. Kitahata MM, Dillingham PW, Chaiyakunapruk N, Buskin SE, Jones JL, Harrington RD, et al. Electronic human immunodeficiency virus (HIV) clinical reminder system improves adherence to practice guidelines among the University of Washington HIV Study Cohort. Clin Infect Dis. 2003;36(6):803-11.

43. White BL, Walsh J, Rayasam S, Pathman DE, Adimora AA, Golin CE. What makes me screen for HIV? Perceived barriers and facilitators to conducting recommended routine HIV testing among primary care physicians in the Southeastern United States. J Int Assoc Provid AIDS Care. 2015;14(2):127-35.

44. McInnes DK, Solomon JL, Bokhour BG, Asch SM, Ross D, Nazi $\mathrm{KM}$, et al. Use of electronic personal health record systems to encourage HIV screening: an exploratory study of patient and provider perspectives. BMC Res Notes. 2011;4:295.

45. Martin EG, Schackman BR. Updating the HIV-testing guidelines-a modest change with major consequences. N Engl J Med. 2013;368(10):884-6.

Publisher's Note Springer Nature remains neutral with regard to jurisdictional claims in published maps and institutional affiliations. 